\title{
How to disinfect anuran eggs? Sensitivity of anuran embryos to chemicals widely used for the disinfection of larval and post-metamorphic amphibians
}

\author{
János Ujszegi $^{1}$ @ | Kinga Molnár ${ }^{2} \quad$ | Attila Hettyey ${ }^{1}$
}

${ }^{1}$ Lendület Evolutionary Ecology Research Group, Plant Protection Institute, Centre for Agricultural Research, Budapest, Hungary

${ }^{2}$ Department of Anatomy, Cell and Developmental Biology, Eötvös Loránd University, Budapest, Hungary

\section{Correspondence}

János Ujszegi, Lendület Evolutionary Ecology Research Group, Plant Protection Institute, Centre for Agricultural Research, Herman Ottó út 15, Budapest, 1022, Hungary.

Email: ujszegi.janos@gmail.com

Funding information

"Lendület" programme of the Hungarian Academy of Sciences, Grant/Award Number: MTA, LP2012-24/2012; FP7 Marie Curie Career Integration Grant, Grant/Award Number: PCIG13-GA-2013-631722; National Research, Development and Innovation Office, Grant/Award Number: NKFIH-K/124375

\begin{abstract}
Emerging infectious diseases are major drivers of global and local amphibian biodiversity loss. Therefore, developing effective disinfection methods to manage the impact of diseases in wild and captive "ark" populations are an important goal in amphibian conservation. While chemical disinfectants have been used safely and effectively in larval and adult amphibians infected with pathogenic microbes, their applicability to amphibian egg masses has remained untested. To bridge this gap, we exposed embryos of the common toad (Bufo bufo) and agile frog (Rana dalmatina) experimentally to three widely used disinfectants: voriconazole, chloramphenicol and chlorogen-sesquihydrate. For 3 days we exposed portions of egg masses to these disinfectants at $1 \times, 2 \times, 5 x$ and $10 x$ the concentration recommended for the disinfection of tadpoles and adults. Subsequently, we recorded embryonic and larval survival, as well as larval body mass and the incidence of abnormalities 12 days after hatching. Application of voriconazole had species- and concentration-dependent negative impacts on survival and body mass, and caused marked malformations in the viscerocranial structure of $B$. bufo tadpoles. Exposure to chlorogen-sesquihydrate also resulted in significant mortality in B. bufo embryos and negatively affected body mass of $R$. dalmatina larvae. Chloramphenicol had little negative effects on embryos or larvae in either species. Based on these results, the application of voriconazole and chlorogen-sesquihydrate cannot be recommended for the disinfection of amphibian eggs, whereas treatment with chloramphenicol appears to be a safe method for eliminating potential pathogens from anuran egg masses and their immediate aquatic environment.
\end{abstract}

\section{KEYWORDS}

amphibian embryos, Batrachochytrium dendrobatidis, chemical exposure, chloramphenicol, voriconazole

\section{1 | INTRODUCTION}

Emerging infectious diseases caused by viral (e.g., ranavirosis), bacterial (e.g., chlamydiosis) and fungal (e.g., chytridiomycosis, saprolegniasis) agents pose a serious threat to amphibians (Blaustein, Grant Hokit,
O'Hara, \& Holt, 1994; Fisher et al., 2012; Kiesecker, Blaustein, \& Belden, 2001; McCallum, 2012), and can threaten the persistence of amphibian populations (Blumer, Zimmermann, Weilenmann, Vaughan, \& Pospischil, 2007; Kiesecker \& Blaustein, 1997; Miaud et al., 2016) and entire species (Scheele et al., 2019; Sutton et al., 2014). 
Captive breeding is widely applied in the conservation of endangered amphibian species (Griffiths \& Pavajeau, 2008; Zippel et al., 2011). Furthermore, amphibians are also increasingly maintained in captivity for the purposes of research, hobby, public display and food production (Densmore \& Green, 2007; Hadfield \& Whitaker, 2005). Fungal, viral and bacterial diseases can cause devastating disease outbreaks in such facilities (Chai et al., 2006; Densmore \& Green, 2007; Miller et al., 2008). The high chance of pathogen transmission by direct or indirect (via caretakers) contact among hosts kept at high density, as well as transportation of subclinically infected individuals into new facilities can cause disease outbreaks. Moreover, infected animals or the pathogens themselves may also escape from facilities contributing to the emergence of introduced diseases in naïve amphibian populations (Garner et al., 2006; Kiesecker, Blaustein, \& Miller, 2001; Schloegel et al., 2012). Finally, species conservation programs can also involve translocations of amphibian egg clutches during which diseases can be spread inadvertently. Therefore, finding suitable methods for preventing the spread of infectious diseases within and beyond captive breeding facilities as well as among natural habitats is of fundamental importance for the conservation of amphibian species (Pessier, 2008).

Chemical disinfection methods are widely used to manage pathogens and diseases in captive amphibian populations. These methods include treatment of tadpoles, metamorphs, juveniles or adults with salt (White, 2006), cytotoxic compounds (Parker, Mikaelian, Hahn, \& Diggs, 2002), antibiotics (Bishop et al., 2009; Densmore \& Green, 2007; Hadfield \& Whitaker, 2005) or antifungal drugs (Baitchman \& Pessier, 2013; Martel et al., 2011) and broad-spectrum disinfectants (Drake, Koeppel, \& Barrows, 2010) However, even though detailed protocols exist describing how tadpoles, juveniles and adults can be disinfected (Murray et al., 2011a, 2011b; Wind, 2002), we found no published information available on appropriate methods for disinfecting amphibian eggs, despite the fact that such procedures have been applied routinely for a long time in fish aquaculture (Hansen \& Falk-Petersen, 2001; Harboe, Huse, \& Oie, 1994; Wagner, Oplinger, \& Bartley, 2012).

Most anurans exhibit external fertilization and spawn eggs into an aquatic environment where embryos are protected by several jelly sheaths and membranes (McDiarmid \& Altig, 1999), which make them more resistant to acute exposure to various chemicals as compared with tadpoles (Berrill, Bertram, McGillivray, Kolohon, \& Pauli, 1994; Berrill, Coulson, McGillivray, \& Pauli, 1998; Edginton, Rouleau, Stephenson, \& Boermans, 2007; Mahaney, 1994; Pauli, Coulson, \& Berrill, 1999). Although the protective layers also defend embryos against infectious agents (Beattie, 1980; Gomez-Mestre, Touchon, \& Warkentin, 2006; Hamdoun \& Epel, 2007), pathogens can adhere to the jelly matrix and thereby travel along with eggs during translocations, infect tadpoles after hatching and may become established in the new natural habitat or laboratory environment (Densmore and Green (2007). For instance, the amphibian chytrid, Batrachochytrium dendrobatidis $(B d)$ is unable to colonize embryos because they lack keratinized structures (Berger, Longcore, Speare, Hyatt, \& Skerratt, 2009), but the waterborne zoospores (infective stage of $B d$ ) are able to survive for several weeks in water and on nonamphibian structures (Johnson \& Speare, 2003, 2005). If present in the surrounding water, $B d$ zoospores, other fungal and bacterial pathogens attached to the egg surface may infect hatching individuals. The development of protocols for the disinfection of amphibian egg masses is therefore an important and promising avenue, because chemicals can easily come into contact with pathogens in the water and on to the surface of the eggs, while embryos are to some extent protected by the jelly coat. However, at the same time, embryonic development is the life stage when the morphological and physiological complexity of the organism unfolds at the highest pace, making this stage particularly vulnerable to extreme external disturbances (Hamdoun \& Epel, 2007; Wilson, 1973). Consequently, whether the protection provided by the external egg layers or the intrinsic vulnerability of the fast-developing embryo prevails when coming into contact with aggressive disinfectants is still yet to be answered.

In this study, we tested for possible negative effects of three disinfectants that are widely used for the treatment of later life stages of amphibians on embryos of the agile frog (Rana dalmatina) and the common toad (Bufo bufo). We investigated the effects of exposure to voriconazole, which is an effective antifungal that kills $B d$ (Martel et al., 2011; Woodward, Berger, \& Skerratt, 2014) and other fungal pathogens such as Aspergillus, Candida and Cryptococcus species (Dickinson et al., 1996), chloramphenicol, which is an antibiotic that is active against a wide range of aquatic bacterial pathogens $(\mathrm{Ho}, \mathrm{Hsu}$, Chen, \& Wang, 2000; Michel, Kerouault, \& Martin, 2003; Nusbaum \& Shotts, 1981) and is effective against Bd (Bishop et al., 2009; Poulter, Bishop, \& Speare, 2016; Young, Speare, Berger, \& Skerratt, 2012), and chlorogen-sesquihydrate, which is a general disinfectant of drinking water, and effective against a wide range of microorganisms (Fráter et al., 2013; Tóth, 1997).

\section{MATERIALS AND METHODS}

\section{1 | Experimental procedures}

In March 2017 we collected 150 eggs from each of 12 freshly laid clutches of the agile frog (Rana dalmatina) from three ponds close to Budapest (four clutches from each locality: $47.644753 \mathrm{~N}, 18.775262$ E; 47.57626 N, 18.86865 E; 47.624990 N, 18.805730 E). We transported eggs to the Experimental Station Júliannamajor of the Plant Protection Institute, Centre for Agricultural Research. During the experiment we kept animals at $19.6 \pm 1.4^{\circ} \mathrm{C}$ (mean $\pm \mathrm{SD}$ ) and adjusted lighting weekly to the actual natural light/dark cycle. We rinsed eggs with reconstituted soft water (RSW; APHA, 1985) and placed them in groups of 10 into opaque plastic boxes $(15.5 \times 11.5 \times 12 \mathrm{~cm})$ containing $500 \mathrm{~mL} \mathrm{RSW}$ with or without disinfectants, depending on the experimental treatment (first day of experiment). On the second and third day, we changed water with freshly prepared disinfectant solutions or clean RSW, according to treatments. On the fourth day, we rinsed eggs, placed them into new boxes containing $500 \mathrm{~mL} \mathrm{RSW}$, and raised embryos until hatching. We exposed embryos to voriconazole 
(VFend; Pfizer), chloramphenicol (Sigma-Aldrich) and chlorogensesquihydrate (Neomagnol; PharmaSwiss) at the recommended concentration (1X), as well as at concentrations 2, 5 and 10 times higher $(2 \times, 5 \times$ and $10 \times)$. Recommended concentrations can be applied safely on tadpoles and/or metamorphosed individuals: $1.25 \mathrm{mg} / \mathrm{L}$ in the case of voriconazole (Martel et al., 2011), $20 \mathrm{mg} / \mathrm{L}$ in the case of chloramphenicol (Poulter et al., 2016; Young et al., 2012) and $10 \mathrm{mg} / \mathrm{L}$ in the case of chlorogen-sesquihydrate, based on the concentration recommended for aquarium fishes. We also tested higher concentrations than recommended to maximize the detectability of adverse effects and to test if elevated concentrations may also be applied to be able to maximize efficacy of disinfection. Because the surrounding jelly may to some extent protect embryos against chemicals present in the environment (Berrill et al., 1994, 1998), we expected that elevated concentrations would not have a strong effect on embryonic survival and development.

We applied two controls: in one we performed daily water change with RSW, in the other we left eggs undisturbed during the entire period of embryonic development. This resulted in 14 treatments (three disinfectants $x$ four concentrations + two controls), each replicated 12 times by exposing a group of 10 embryos of each family entering treatments, totaling 1680 embryos in 168 experimental replicates. Treatments were arranged in a randomized spatial block design, where each block contained members of one family and all treatments.

After hatching, we removed the jelly and dead embryos from containers and reared surviving tadpoles for twelve more days in the same plastic boxes. We fed tadpoles with boiled and crushed spinach ad libitum, and changed water 7 days after hatching. At the end of the experiment, we counted survivors and measured body mass of tadpoles to the nearest $0.1 \mathrm{mg}$ with a digital scale. We also noted gross deformities visible to the naked eye. After termination of the experiment we released survivors at the site of their collection.

At the end of March, we collected 200 eggs from each of 12 egg strings of the common toad (Bufo bufo) from two localities (6-6 strings from $47.57626 \mathrm{~N}, 18.86865 \mathrm{E}$ and $47.624990 \mathrm{~N}, 18.805730 \mathrm{E}$ ), and conducted the same experiment as described above with the following differences: (i) because of the egg string's structure, we were not able to separate eggs into groups of 10 , and therefore the initial number of eggs per box varied between eight and 17 (mean \pm SD, $11.9 \pm 1.3$; median $=12$; ; (ii) the highest $(10 x)$ concentration of chlorogen-sesquihydrate was not applied, because of the unexpectedly high mortality observed in R. dalmatina embryos (see Section 3); and (iii) in some clutches, embryos hatched before the termination of experimental exposure to chemical disinfectants (for details see below).

The General Department for Environmental and Nature Protection of Érdi Járási Hivatal (Pest Megyei Kormányhivatal) issued the permission to conduct the study (PE06/KTF/8060-1-2/2018) and the Ethical Commission of the MTA ATK NÖVI approved the investigation in accordance with Good Scientific Practice guidelines and national legislation.

\section{2 | Preparation of specifically deformed individuals of voriconazole treatments}

At the end of the experiment, we placed individuals with specific viscerocranial deformities into clear RSW for 10 minutes to clear their gills, and subsequently killed them using MS 222 (tricaine methanesulfonate; $3 \mathrm{~g} / \mathrm{L}$ ). Some of these tadpoles (five from controls, three from each of the $1 \times, 2 \times$ and $5 \times$ voriconazole treatments and five from the $10 \times$ voriconazole treatment) were later prepared and stained using modified whole-mount skeletal staining to visualize cartilages (for details, Data S1 [see Supporting Information], and Wassersug, 1976). We examined stained tadpoles using light microscopy at $\times 10$ magnification.

\section{3 | Statistical analyses}

We performed analyses on the two species separately. In the case of $R$. dalmatina we had to exclude one clutch from the analyses because it exhibited unusually high mortality across all treatments including the control treatments (where $40 \%$ of embryos died). Because exposure to the highest concentration of chlorogen-sesquihydrate (10x the recommended dose) resulted in almost $100 \%$ mortality of embryos, this treatment was not included in analyses of larval traits. The two control treatment groups did not differ significantly in the case of either investigated variable or species (all $P>.44$ ), so that we used pooled controls in all analyses. We analyzed mortality with Cox regression using the "coxme" function in the "coxme" package in " $R$ " (R Development Core Team 2016; http://www.r-project.org/) by entering treatment as a fixed factor and family as a random factor. We analyzed the mean tadpole body mass calculated for experimental units using linear mixed modeling procedures (LMM). Models included treatment as a fixed factor and family as a random factor. We checked model fit by observing diagnostic plots and used Dunnett's tests in the "Ismeans" package to compare each treatment group with controls. Because of a highly zero-inflated distribution, we analyzed deformity rate using nonparametric Fisher tests comparing the number of deformed individuals in each treatment one by one with controls. In the end, we adjusted $P$ values using the false discovery rate method (Benjamini \& Hochberg, 1995). We also assessed deformity rate by performing Fisher tests on the number of experimental replicates containing at least one deformed individual (for results, Data S2; see Supporting Information).

In the case of $B$. bufo, we excluded from the analyses one clutch where eggs did not show any sign of development and excluded one experimental unit from the analysis on deformity rate (chloramphenicol $1 \times$ treatment) because of missing data. We applied the same statistical methods as described above for $R$. dalmatina with one exception: because some clutches hatched before the end of experimental exposure (within the first 3 days), we also entered hatching time (during or after the end of chemical exposure) as a factor and its interaction with treatment into Cox regression and LMM models. We also took into account hatching time regarding deformity rate and 
analyzed data separately using Fisher tests. All animals survived that hatched during chemical exposure in the groups exposed to chlorogen-sesquihydrate at $2 x$ and $5 x$ concentrations. Similarly, all animals survived that hatched after exposure to chloramphenicol at the recommended concentration. We could not enter these groups with zero variance into survival analyses, so we excluded them from Cox regressions and examined the effect of hatching time on mortality in these three treatments one by one using nonparametric Fisher tests. We used the "type = 2" function of ANOVA in the "car" package in "R" (R Development Core Team 2016; http://www.r-project.org/) to obtain relevant statistics. Statistics were calculated using $R$ 3.4.0 for Windows.

\section{RESULTS}

Mortality in $R$. dalmatina differed significantly among treatments (Cox regression; $\chi^{2}=487.93, \mathrm{df}=13, P<.001$; Table 1, Figure $\left.1 \mathrm{~A}\right)$. Dunnett's post-hoc tests revealed that embryo survival was significantly lower in the $10 x$ voriconazole and $5 x$ and $10 x$ chlorogensesquihydrate treatments than in the controls. In the case of $B$. bufo, mortality levels depended on the interaction between treatment and hatching time (i.e., hatching during or after exposure to chemical disinfectants; $\left.\chi^{2}=28.48, \mathrm{df}=9, P<.001\right)$. For clutches that hatched during exposure (i.e., on the first, second or third day of the experiment) only the $5 x$ and $10 x$ voriconazole treatments led to increased mortality (Table 2, Figure 2A1 and A2). When hatching occurred after the end of chemical exposure (i.e., on the fourth or fifth day of the experiment), treatment with voriconazole at the recommended concentration also resulted in increased mortality. In individuals that hatched during exposure to the recommended concentration of chloramphenicol we observed no significant increase in mortality rate, but when tadpoles hatched after exposure, mortality rate was significantly lower than in controls (Table 2). Exposure to the $2 \times$ concentration of chlorogen-sesquihydrate had no significant effect on mortality rate, either when hatching occurred during or after exposure. Finally, the $5 \times$ concentration of chlorogen-sesquihydrate had no effect on mortality rate when individuals hatched during exposure, but mortality was significantly increased when individuals hatched after exposure.

Body mass of $R$. dalmatina tadpoles differed significantly among treatments $\left(\mathrm{LMM} ; \chi^{2}=1443.6, \mathrm{df}=12, P<.001\right.$; Table 1, Figure $1 \mathrm{~B}$, Data S3 [see Supporting Information]): it was lower than in controls when voriconazole was present at a concentration higher than the recommended dose (i.e., $2 \times, 5 \times$ and $10 \times$ ), at the highest concentration of chloramphenicol $(10 \times)$, and at two concentrations of chlorogen-sesquihydrate ( $1 \times$ and $5 x$; the $10 x$ concentration could not be analyzed because only one individual survived). Body mass of B. bufo tadpoles was affected by the interaction between treatment and hatching time (LMM; $\chi^{2}=101.92, \mathrm{df}=12, P<.001$; Table 3, Figure 2B1 and B2, Data S3 [see Supporting Information]): exposure to all concentrations of voriconazole resulted in a large decrease in body mass (by about 50\%) relative to controls, but this decrease was more pronounced in individuals that hatched after the end of exposure to voriconazole.

The deformity rate in $R$. dalmatina tadpoles exposed to the $10 \times$ voriconazole treatment was significantly higher (21 deformed of 95 individuals) than in controls (four deformed of 214 individuals; Fisher test; $P<.001$; Figure $1 \mathrm{C}$ ). The $5 \times$ chlorogen-sesquihydrate treatment also significantly increased the incidence of deformities (seven deformed of 84 individuals; Fisher test; $P=.020$ ). Deformities

TAB LE 1 Effects of treating eggs with disinfectants at $1 \times, 2 \times, 5 \times$ or $10 \times$ the concentration recommended for use in larval or adult amphibians on embryonic mortality and tadpole body mass in Rana dalmatina. Statistics were obtained using Cox regression in the case of mortality and linear mixed modeling procedures in the case of body mass, followed by Dunnett's pairwise tests comparing each treatment with the control. Effect of chlorogen-sesquihydrate at the $10 \times$ concentration on body mass could not be calculated because only one individual survived. Significant effects are highlighted in bold. In the case of LMM analyses, the residual degree of freedom $=118$. $N=$ number of experimental units in each treatment

\begin{tabular}{|c|c|c|c|c|c|c|c|}
\hline \multirow[b]{2}{*}{ Treatment } & \multicolumn{4}{|c|}{ Mortality rate (Cox) } & \multicolumn{3}{|c|}{ Body mass (LMM) } \\
\hline & Estimate & Lower Cl & Upper Cl & $P$ & $N$ & $t$-ratio & $P$ \\
\hline Voriconazole $1 \times$ & 3.33 & -0.32 & 2.73 & .21 & 11 & -2.5 & .10 \\
\hline Voriconazole $2 \times$ & 2.15 & -0.89 & 2.43 & .76 & 11 & -9.0 & $<.001$ \\
\hline Voriconazole $5 x$ & 0.35 & -4.09 & 1.99 & .91 & 11 & -20.9 & $<.001$ \\
\hline Voriconazole $10 x$ & 5.44 & 0.29 & 3.10 & .01 & 11 & -18.4 & $<.001$ \\
\hline Chloramphenicol $1 \times$ & 1.79 & -1.15 & 2.32 & .92 & 11 & 0.0 & 1.00 \\
\hline Chloramphenicol $2 x$ & 0.70 & -2.67 & 1.96 & 1.00 & 11 & -1.4 & .70 \\
\hline Chloramphenicol $5 x$ & 1.06 & -1.96 & 2.07 & 1.00 & 11 & -1.9 & .37 \\
\hline Chloramphenicol 10x & 1.43 & -1.49 & 2.21 & 0.99 & 10 & -7.2 & $<.001$ \\
\hline Chlorogen-sesquihydrate $1 \times$ & 1.80 & -1.15 & 2.32 & 0.92 & 11 & -3.1 & .03 \\
\hline Chlorogen-sesquihydrate $2 \times$ & 1.80 & -1.15 & 2.32 & 0.92 & 10 & -1.9 & .34 \\
\hline Chlorogen-sesquihydrate $5 \times$ & 10.65 & 1.04 & 3.69 & $<.001$ & 11 & -4.1 & $<.001$ \\
\hline Chlorogen-sesquihydrate $10 x$ & 102.71 & 3.37 & 5.89 & $<.001$ & - & - & - \\
\hline
\end{tabular}




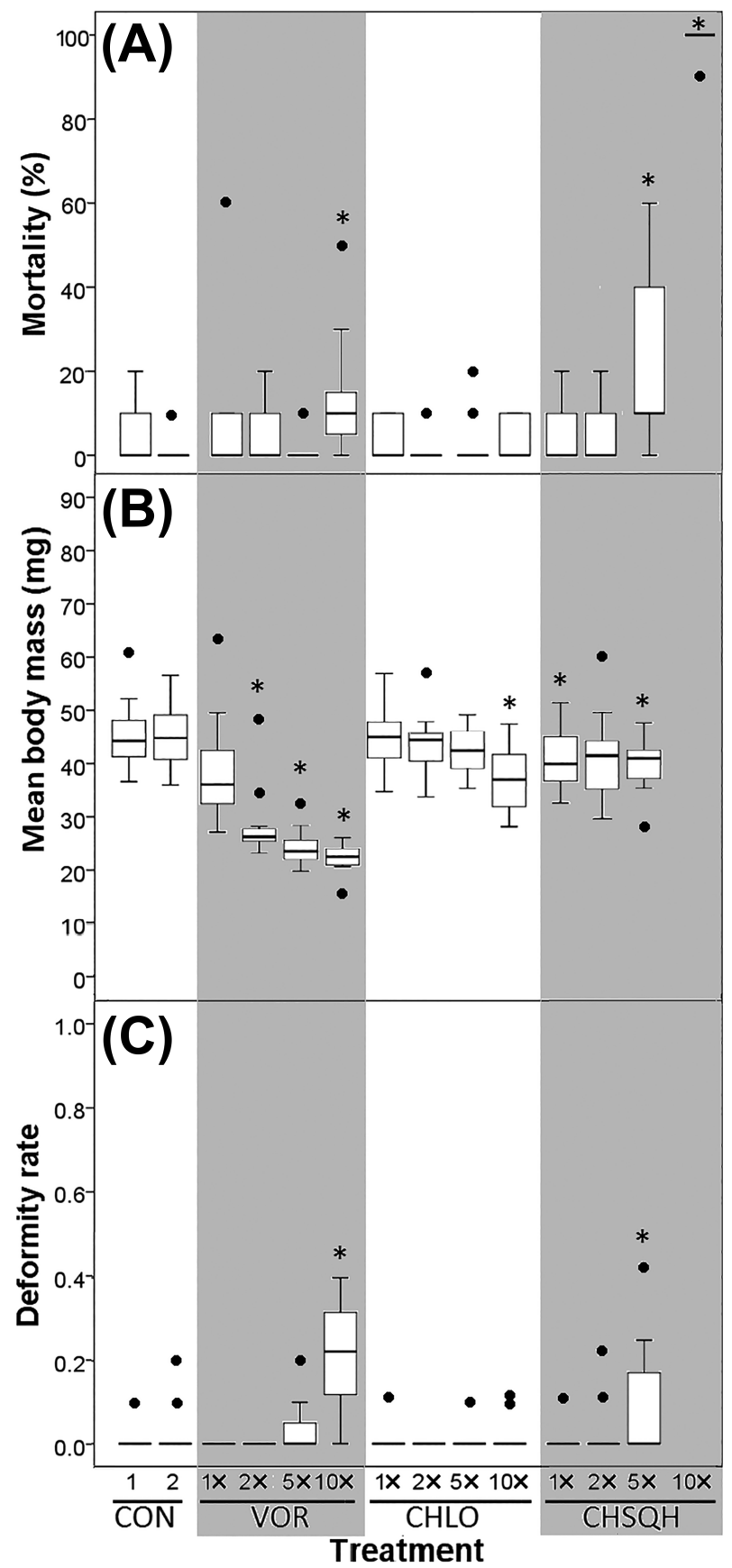

FIGURE 1 Mortality rate (A), mean tadpole mass (B) and deformity rate (C) in Rana dalmatina controls (CON 1, 2) and after exposure of eggs to different concentrations of voriconazole (VOR), chloramphenicol (CHLO) and chlorogen-sesquihydrate $(\mathrm{CHSQH})$. Applied concentrations in relation to the concentrations recommended for use in amphibian larvae or adults are indicated $(1 \times, 2 \times, 5 \times, 10 \times)$. CON 1 refers to controls with water change, CON 2 to controls without water change during embryonic development. Chlorogen-sesquihydrate at the $10 \times$ concentration is missing from panel $B$ and $C$ because only one individual survived in this treatment (see panel A). Vertical lines depict medians, boxes represent interquartiles, bars represent ranges, and dots indicate outliers (deviating from the boundary of the interquartile range by a factor greater than 1.5 ). Asterisks mark cases with significant difference from the controls were not significantly more frequent in other treatment groups than in controls (all $P>$.4). In $B$. bufo tadpoles, the lowest concentration of voriconazole significantly increased the incidence of deformities compared with controls, both when hatching occurred before (21 deformed of 30 individuals vs. one deformed of 107 individuals in controls) and after (35 deformed of 65 individuals vs. two deformed of 133 individuals in controls) the end of exposure (Fisher tests; both $P<.001$; Figure 2C1 and C2). In treatment groups treated with higher concentrations of voriconazole deformity rate was $100 \%$. Exposure to chloramphenicol or chlorogen-sesquihydrate did not result in increased incidence of deformities at any concentration. Fisher tests on the number of experimental replicates containing at least one deformed individual gave very similar results (Data S2 [see Supporting Information]).

We detected a specific deformity in B. bufo tadpoles exposed to voriconazole during their embryonic development: tadpoles exhibited a funnel-shaped, concave angular head, often coupled with a vertically or horizontally bent spine (Figure 3 ). In the $1 \times, 2 x$ and $5 \times$ voriconazole treatments we observed that the Meckel's and palatoquadratum cartilages (related to the first pharyngeal arch) were underdeveloped or deformed compared with controls. The ceratohyal cartilage (biggest cartilage of the second pharyngeal arch) was also smaller and malformed. These three cartilages were completely lacking in the $10 \times$ voriconazole treatment (Figure 3). These deformities appeared already at the recommended concentration, and were present in all animals at higher concentrations.

\section{DISCUSSION}

In this study, we tested the applicability of three disinfectants on embryos of the agile frog ( $R$. dalmatina) and the common toad (B. bufo). We found that one of the chemical disinfectants, chloramphenicol, can be safely applied for acute disinfection of anuran eggs, because we did not observe any negative effect on developing embryos and hatching larvae even at a concentration $5 \times$ higher than that recommended for the disinfection of adults. Thus we suggest that application of chloramphenicol would be a good candidate to disinfect anuran egg masses at a concentration of $100 \mathrm{mg} / \mathrm{L}$ for 3 days. Conversely, voriconazole and chlorogen-sesquihydrate had adverse effects on developing embryos at the concentration recommended for use on tadpoles and metamorphosed frogs.

Voriconazole is an effective antifungal disinfectant that is successfully applied against $B d$ on anuran tadpoles at a concentration of $1.25 \mathrm{mg} / \mathrm{L}$ with the treatment lasting for 7 days, and even a 10 times higher concentration has no adverse effects on larvae and juveniles (Martel et al., 2011; also see Data S4 [see Supporting Information] for an experimental test using $B$. bufo tadpoles detecting no adverse effect). We found that hatching larvae of $R$. dalmatina were not affected negatively by treatment with $1.25 \mathrm{mg} / \mathrm{L}$ concentration during embryonic development. However, embryonic exposure to higher concentrations of voriconazole resulted in a drastically decreased body mass, and at $10 \times$ concentration we observed elevated rates of 
TAB LE 2 Effects of treating eggs with disinfectants at $1 \times, 2 \times, 5 \times$ or $10 \times$ the concentration recommended for use in larval or adult amphibians on mortality rate of Bufo bufo embryos. We obtained statistics using Cox regression followed by Dunnett's pairwise tests comparing treatment groups with the control. Because the interaction between treatment and hatching time was significant, we present results on individuals that hatched during or after treatments separately. Chlorogen-sesquihydrate was not applied to $B$. bufo at the $10 \times$ concentration because of its devastating effect on $R$. dalmatina embryos. Significant effects are highlighted in bold

\begin{tabular}{|c|c|c|c|c|c|c|c|c|}
\hline \multirow[b]{2}{*}{ Treatment } & \multicolumn{4}{|c|}{ Hatching during exposure } & \multicolumn{4}{|c|}{ Hatching after exposure } \\
\hline & Estimate & Lower Cl & Upper Cl & $P$ & Estimate & Lower $\mathrm{Cl}$ & Upper Cl & $P$ \\
\hline Voriconazole $1 \times$ & 1.48 & -2.11 & 2.89 & .99 & 8.55 & 1.13 & 3.16 & $<.001$ \\
\hline Voriconazole $2 x$ & 0.69 & -3.50 & 2.76 & 1.00 & 8.51 & 1.14 & 3.15 & $<.001$ \\
\hline Voriconazole $5 x$ & 10.34 & 0.54 & 4.13 & $<.001$ & 3.52 & 0.13 & 2.38 & .02 \\
\hline Voriconazole $10 x$ & 9.92 & 0.50 & 4.09 & $<.001$ & 12.96 & 1.57 & 3.55 & $<.001$ \\
\hline Chloramphenicol $1 \times$ & - & - & - & $1.00^{*}$ & - & - & - & $.02^{* *}$ \\
\hline Chloramphenicol $2 x$ & 0.68 & -3.51 & 2.75 & 1.00 & 1.93 & -0.61 & 1.93 & .60 \\
\hline Chloramphenicol $5 x$ & 1.40 & -2.16 & 2.83 & .99 & 0.18 & -4.55 & 1.08 & .44 \\
\hline Chloramphenicol 10x & 1.41 & -2.15 & 2.84 & .99 & 1.61 & -0.83 & 1.79 & .84 \\
\hline Chlorogen-sesquihydrate $1 \times$ & 3.60 & -0.74 & 3.31 & .41 & 1.09 & -1.33 & 1.50 & 1.00 \\
\hline Chlorogen-sesquihydrate $2 x$ & - & - & - & $.61^{*}$ & - & - & - & $.55^{*}$ \\
\hline Chlorogen-sesquihydrate $5 x$ & - & - & - & $.55^{*}$ & - & - & - & $<.001^{*}$ \\
\hline
\end{tabular}

"Calculated using Fisher test.

"Positive effect: mortality rate was significantly lower in this treatment group than in the controls.

mortality and deformities. Furthermore, embryonic exposure to voriconazole had strong negative effects already at a concentration of $1.25 \mathrm{mg} / \mathrm{L}$ on survival and body mass of hatching B. bufo tadpoles.

In our study, voriconazole proved to be highly teratogenic when applied to $B$. bufo embryos: many tadpoles developing from embryos exposed to the concentration recommended for tadpole disinfection had a malformed head and spine. The incidence of these deformities increased to $100 \%$ at all concentrations of voriconazole which were higher than the recommended. The deformed head severely interfered with feeding, as evidenced by the lack of feces in relevant rearing containers and reduced growth compared with individuals in the control treatment. The malformed head shape resulted from abnormal development of the viscerocranium, which is a known effect of azole fungicides, observed particularly when exposure occurs during neurulation (Tiboni, 1993; Groppelli et al., 2005; Zoupa \& Machera, 2017; for details see Data S5 [see Supporting Information]). We originally expected to find stronger malign effects of voriconazole in B. bufo clutches that hatched before the end of exposure, and where hatching larvae came into direct contact with the chemical, but exposure to voriconazole resulted in higher mortality in clutches that hatched after the end of the treatment. Furthermore, voriconazole applied at the recommended concentration (and any higher concentration) during embryonic development resulted in significantly lowered body mass of $B$. bufo tadpoles, and this effect was also more pronounced in the case of individuals that hatched after the end of the treatment. A likely explanation for these unexpected results is that early-hatching individuals were more advanced in their development during exposure to the chemical than animals that hatched late, so that the former were not exposed to voriconazole in the most sensitive phase of their development (i.e., during neurulation), whereas the latter came into contact with voriconazole during that period. The absence of abnormal head shape in $R$. dalmatina suggests that embryos of this species are less sensitive to voriconazole or are better protected by the thicker jelly surrounding eggs of this species (Nöllert \& Nöllert, 1992). However, tadpoles of $R$. dalmatina exposed to voriconazole as embryos exhibited lower body mass than control animals indicating possible sublethal effects in this species as well. Thus, overall and similar to other azole fungicides (Groppelli et al., 2005; Papis, Bernardini, Gornati, \& Prati, 2006) voriconazole appears harmful to developing embryos and should not be considered suitable for in vivo disinfection of egg masses.

Chloramphenicol is known to be effective against $B d$ and can safely be applied to adult amphibians at concentrations of $20 \mathrm{mg} / \mathrm{L}$ for several days (Bishop et al., 2009; Poulter et al., 2016; Young et al., 2012). In our study, embryonic exposure to chloramphenicol at up to $5 \times$ the recommended dose $(100 \mathrm{mg} / \mathrm{L})$ had no effect on survival, body mass and occurrence of developmental malformations in either species. In addition, embryonic exposure to $10 \times$ the recommended dose of chloramphenicol had no detectable effect on B. bufo individuals and resulted in only a slight reduction in body mass of $R$. dalmatina tadpoles. It therefore appears that chloramphenicol can be used safely for the disinfection of egg masses of $R$. dalmatina and B. bufo, and most likely of other ranid and bufonid species too.

While concerns have been raised about possible side-effects of chloramphenicol on amphibians, it appears unlikely that these apply to anuran embryos. El-Mofty, Abdelmeguid, Sadek, Essawy, and Abdel Aleem (2000) for example, reported chloramphenicol-induced leukemia in adult frogs, but the concentration applied to experimental animals was 500 times higher than the recommended concentration of 20 mg/L (Bishop et al., 2009; Young et al., 2012) with exposure lasting for 3 months. In addition, while chloramphenicol may disrupt the natural skin microbiota of adult frogs (Holden, Ebert, Canning, \& 


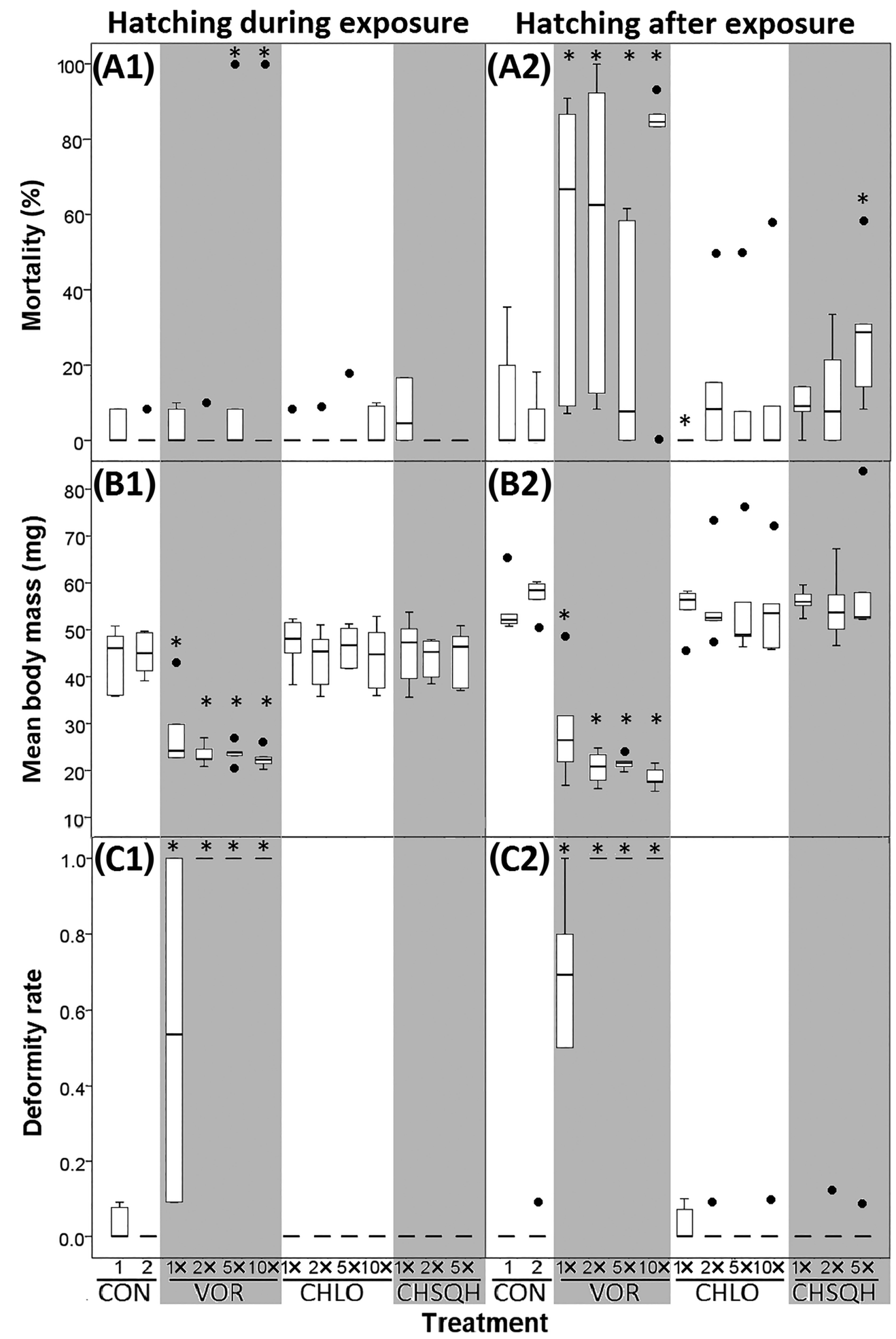

FIGURE 2 Mortality rate (A1 and 2), mean tadpole mass (B1 and 2) and deformity rate (C1 and 2) in case of Bufo bufo in controls (CON 1, 2) and after exposure of eggs to different concentrations of voriconazole (VOR), chloramphenicol (CHLO) and chlorogen-sesquihydrate (CHSQH). Applied concentrations in relation to the concentrations recommended for use in amphibian larvae or adults are indicated ( $1 \times, 2 \times, 5 \times, 10 \times)$. CON 1 refers to controls with water change, CON 2 to controls without water change during embryonic development. We did not apply chlorogensesquihydrate to $B$. bufo at the $10 \times$ concentration because of its devastating effect on $R$. dalmatina embryos. Because the interaction between treatment and hatching time was significant in case of mortality rate and body mass, results on individuals that hatched during or after the end chemical exposure are presented separately (column 1 and 2). Vertical lines depict medians, boxes represent interquartiles, bars represent ranges, and dots indicate outliers (deviating from the boundary of the interquartile range by a factor greater than 1.5). Asterisks mark cases with significant difference from the controls 
TAB LE 3 Effects of treating eggs with disinfectants at $1 \times, 2 \times, 5 \times$ or $10 \times$ the concentration recommended for use in larval or adult amphibians on body mass of Bufo bufo tadpoles. We obtained statistics using linear mixed modeling procedures followed by Dunnett's pairwise tests comparing treatments with the control. Because the interaction between treatment and hatching time was significant, we present results on individuals that hatched during or after treatments separately. We did not apply chlorogen-sesquihydrate to $B$. bufo at the $10 \times$ concentration because of its devastating effect on $R$. dalmatina embryos. Significant effects are highlighted in bold. Residual degree of freedom $=105 . N=$ number of experimental units in each treatment $\times$ hatching time group

\begin{tabular}{|c|c|c|c|c|c|c|}
\hline Treatment & \multicolumn{3}{|c|}{ Hatching during exposure } & \multicolumn{3}{|c|}{ Hatching after exposure } \\
\hline Voriconazole $1 \times$ & 6 & -3.92 & .002 & 5 & -5.78 & $<.001$ \\
\hline Voriconazole $2 x$ & 6 & -12.68 & $<.001$ & 4 & -18.24 & $<.001$ \\
\hline Voriconazole $5 \times$ & 5 & -13.02 & $<.001$ & 5 & -20.33 & $<.001$ \\
\hline Voriconazole $10 x$ & 5 & -13.34 & $<.001$ & 5 & -21.60 & $<.001$ \\
\hline Chloramphenicol $2 x$ & 6 & -0.13 & 1.00 & 5 & -0.02 & 1.00 \\
\hline Chloramphenicol $5 \times$ & 6 & 0.55 & .99 & 5 & -0.17 & 1.00 \\
\hline Chloramphenicol $10 x$ & 6 & -0.05 & 1.00 & 5 & -0.28 & 1.00 \\
\hline Chlorogen-sesquihydrate $1 \times$ & 6 & 0.51 & .99 & 5 & 0.12 & 1.00 \\
\hline
\end{tabular}

Rollins-Smith, 2014), this is unlikely to be a problem when disinfecting egg masses. Besides clearing $B d$, chloramphenicol is also highly effective against bacterial pathogens at a concentration of $100 \mathrm{mg} / \mathrm{L}$, similar to our recommendation (Ho et al., 2000; Michel et al., 2003), increasing its utility as a disinfectant of egg masses. While effective at killing $B d$ and bacterial pathogens, chloramphenicol may not be effective against pathogenic fungi other than $B d$ (e.g., Saprolegnia sp.) and as such, chloramphenicol may need to be used in combination with a nonazole fungicide to protect embryos better, and thereby also hatchlings, against pathogenic fungi other than $B d$.

Chlorogen-sesquihydrate or chloramine-B (the active ingredient of Neomagnol) is a broad-spectrum disinfectant widely used in human medicine and agriculture (Fráter et al., 2013; Tóth, 1997), and may be considered a suitable general disinfectant against aquatic fungal and bacterial pathogens. This chemical is also recommended for use with aquarium fishes, while chloramine-T, the methylated form of chloramine- $B$, has been shown to be highly effective against the fish pathogen, Aeromonas salmonicida and amphibian fungal pathogens: Batrachochytrium salamandrivorans and Bd (Cipriano et al., 1996; Van Rooij, Pasmans, Coen, \& Martel, 2017). However, studies on tadpoles suggest that chlorinated disinfectants can be harmful even at low concentrations (Diana, Beasley, \& Wright, 2001). In our study, all individuals of $R$. dalmatina died when embryos were exposed to $10 \times$ the recommended concentration of chlorogen-sesquihydrate and mortality was significantly elevated both in $R$. dalmatina and in B. bufo when embryos were treated with $5 x$ the recommended concentration. Exposure to the latter concentration caused developmental deformities in the case of $R$. dalmatina individuals too. Consequently, it seems that egg capsules cannot provide embryos with an efficient protection against this disinfectant. Embryonic exposure to chlorogensesquihydrate had a clear negative effect on body mass after hatching in $R$. dalmatina, but not in B. bufo. The latter result suggests that anuran species may differ in their sensitivity to embryonic exposure to chlorogen-sesquihydrate. Applicability of this disinfectant needs further investigation and may be used safely only on a relatively few anuran species.

In an additional experiment (Data S6; see Supporting Information) we also tested the applicability of elevating environmental temperature for egg disinfection, as suggested for larvae and adults against $B d$ and other cold-adapted pathogens (Hettyey et al., 2019). We exposed embryos of $R$. dalmatina and B. bufo to $20,28,30,32$ and $34^{\circ} \mathrm{C}$ in aerated RSW during the entire embryonic stage. Elevated temperature was very harmful to developing embryos of the tested species: almost all individuals exposed to $\geq 30^{\circ} \mathrm{C}$, died (for details, Data S6 and S7 [see Supporting Information]). Thus, this approach cannot be recommended as a method of disinfection for embryos.

Previous studies found that amphibian embryos are more sensitive to environmental stressors/toxicants than adult or larval amphibians, and sensitivity can vary among developmental stages (Blaustein, Romansic, Kiesecker, \& Hatch, 2003; Bridges, 2000; Mikó, Ujszegi, \& Hettyey, 2017). The results of the present study indicate that amphibian embryos are also more sensitive to antifungal and antibacterial disinfectants than other life stages, and show that sensitivity to these treatments may also vary significantly among amphibian species. Overall, our results suggest that the chemical disinfectants voriconazole and chlorogen-sesquihydrate cannot be used on anuran egg masses, while chloramphenicol can be applied safely, which has been shown to be effective against Bd (Bishop et al., 2009; Laurila, Pakkasmaa, Crochet, \& Merilä, 2002; Poulter et al., 2016; Young et al., 2012) and bacterial pathogens (Ho et al., 2000; Michel et al., 2003; Nusbaum \& Shotts, 1981). 


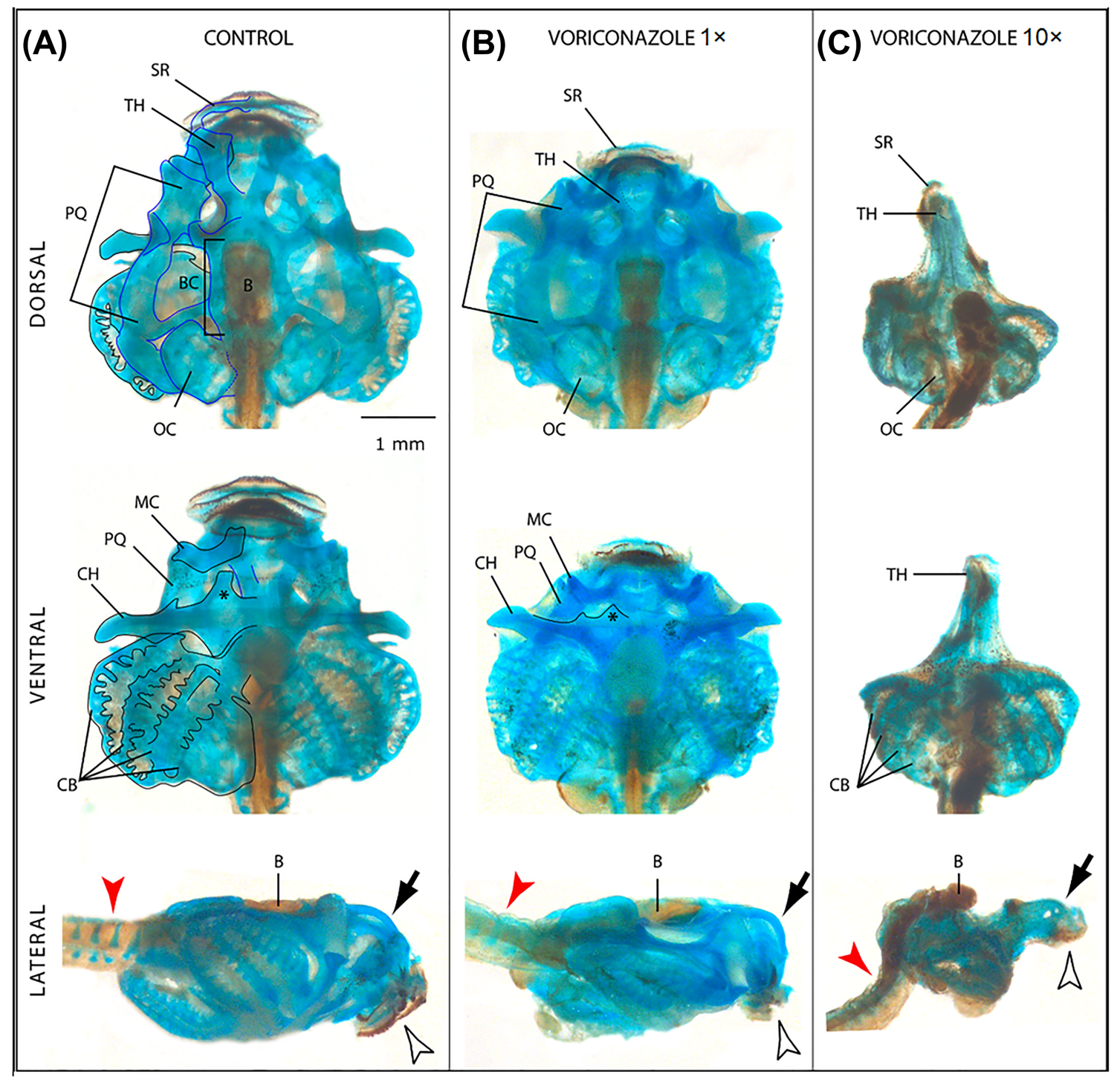

FIGURE 3 Chondrocranium of Bufo bufo tadpoles after whole-mount skeletal staining in a control animal (A) and after embryonic exposure to voriconazole in the $1 \times$ (panel B) or $10 \times$ (panel C) concentration treatment photographed at $\times 10$ magnification. Dorsal views are uppermost, ventral views are in the middle and lateral views are at the bottom of the figure. A) Cartilages of neuro- and viscerocranium of an untreated control specimen: braincase $(\mathrm{BC})$, otic capsule $(\mathrm{OC})$, palatoquadrate $(\mathrm{PQ})$, trabecular horns ( $\mathrm{TH}$, dorsal view) and derivatives of pharyngeal arches (ventral view) are well developed (CB - ceratobranchyal cartilages, $\mathrm{CH}$ - ceratohyal cartilage, $\mathrm{MC}$ - Meckel's cartilage). Trabecular horns have a moderate curvature (lateral view, black arrow) that determines the position of the mouth (white arrowhead). Planes of the neurocranium and the vertebral column (red arrowhead) are almost parallel. B) Chondrocranium of a tadpole after exposure to $1.25 \mathrm{mg} / \mathrm{L}$ voriconazole during embryonic development: otic capsule (OC), braincase (dorsal view) and branchial arches (ventral view) are unaffected, but trabecular horns (TH, dorsal view), the anterior part of the palatoquadrate (PQ), the ceratohyal cartilage $(\mathrm{CH})$, its anterio-medial projection (black asterisk) and Meckel's cartilage (MC, ventral view) are remarkably underdeveloped compared to those in the control specimen. Trabecular horns bend at right angles (black arrow, lateral view), so that the mouth is directed downwards (white arrowhead). The planes of the vertebral column and of the neurocranium are misaligned (red arrowhead). C) Cranial morphology after embryonic exposure to $12.5 \mathrm{mg} / \mathrm{L}$ voriconazole: The suprarostral cartilage (SR) is smaller, trabecular horns (TH) are shorter and almost parallel to each other (dorsal view). Ceratobranchyal cartilages (CB) are identifiable, but the palatoquadrate (dorsal view), ceratohyal and Meckel's cartilages (ventral view) are missing. The anterior part of the skull is formed only by mediodorsal elements (black arrow indicates trabecular horns), the mouth is hypognath (white arrowhead), and the vertebral column is severely curved (red arrowhead, lateral view) (B - brain)

\section{ACKNOWLEDGEMENTS}

We would like to thank M. Szederkényi, E. Karlik, P. Katona and T. Drexler their assistance during the experiment, V. Bókony and B. Üveges for their help with statistics and M. Truszka for preparing specimens for skeletal staining. Funding was provided by the "Lendület" programme of the Hungarian Academy of Sciences (MTA, LP2012-24/2012), an FP7 Marie Curie Career Integration Grant (PCIG13-GA-2013-631722) and by the National Research, Development and Innovation Office (NKFIH$\mathrm{K} / 124375)$. 


\section{CONFLICT OF INTEREST}

The authors have no conflict of interest to report.

\section{ORCID}

János Ujszegi (D) https://orcid.org/0000-0002-6030-0772

\section{REFERENCES}

APHA. (1985). Standard methods for the examination of water and wastewater (16th ed.). Washington DC: American Public Health Association.

Baitchman, E. J., \& Pessier, A. P. (2013). Pathogenesis, diagnosis, and treatment of amphibian chytridiomycosis. Veterinary Clinics of North America - Exotic Animal Practice, 16(3), 669-685. https://doi.org/10.1016/j. cvex.2013.05.009

Beattie, R. C. (1980). A physico-chemical investigation of the jelly capsules surrounding eggs of the common frog (Rana temporaria temporaria). Journal of Zoology, 190, 1-25.

Benjamini, Y., \& Hochberg, Y. (1995). Controlling for false discovery rate: A practical and powerful approach to multiple testing. Journal of the Royal Statistical Society, 67, 289-300.

Berger, L., Longcore, J. E., Speare, R., Hyatt, A. D., \& Skerratt, L. F. (2009). Fungal diseases of amphibians. In $\mathrm{H}$. Heatwole \& J. W. Wilkinson (Eds.), Amphibian biology (Vol. 8) (pp. 2986-3052). Baulkham Hills: Surrey Beatty \& Sons.

Berrill, M., Bertram, S., McGillivray, L., Kolohon, M., \& Pauli, B. (1994). Effects of low concentrations of forest-use pesticides on frog embryos and tadpoles. Environmental Toxicology and Chemistry, 13(4), 657-664. https://doi.org/10.1002/etc.5620130416

Berrill, M., Coulson, D., McGillivray, L., \& Pauli, B. (1998). Toxicity of endosulfan to aquatic stages of anuran amphibians. Environmental Toxicology and Chemistry, 17(9), 1738-1744. https://doi.org/10.1897/ 1551-5028(1998)017<1738:TOETAS > 2.3.CO;2

Bishop, P. J., Speare, R., Poulter, R., Butler, M., Speare, B. J., Hyatt, A., ... Haigh, A. (2009). Elimination of the amphibian chytrid fungus Batrachochytrium dendrobatidis by Archey's frog Leiopelma archeyi. Diseases of Aquatic Organisms, 84(1), 9-15. https://doi.org/10.3354/ dao02028

Blaustein, A. R., Grant Hokit, D., O'Hara, R. K., \& Holt, R. A. (1994). Pathogenic fungus contributes to amphibian losses in the pacific northwest. Biological Conservation, 67(3), 251-254. https://doi.org/10.1016/ 0006-3207(94)90616-5

Blaustein, A. R., Romansic, J. M., Kiesecker, J. M., \& Hatch, A. C. (2003). Ultraviolet radiation, toxic chemicals and amphibian population declines. Diversity and Distributions, 9, 123-140. https://doi.org/10. 1890/1540-9295(2003)001[0087:TCODA]2.0.CO;2

Blumer, C., Zimmermann, D. R., Weilenmann, R., Vaughan, L., \& Pospischil, A. (2007). Chlamydiae in free-ranging and captive frogs in Switzerland. Veterinary Pathology, 44(2), 144-150. https://doi.org/10. 1354/vp.44-2-144

Bridges, C. M. (2000). Long-term effects of pesticide exposure at various life stages of the southern leopard frog (Rana sphenocephala). Archives of Environmental Contamination and Toxicology, 39(1), 91-96. https:// doi.org/10.1007/s002440010084

Chai, N., Deforges, L., Sougakoff, W., Truffot-Pernot, C., Amaury, D. L., Demeneix, B., ... Bomsel, M. C. (2006). Mycobacterium szulgai infection in a captive population of African clawed frogs (Xenopus tropicalis). Journal of Zoo and Wildlife Medicine, 37(1), 55-58. https://doi.org/10. 1638/04-064.1

Cipriano, R. C., Ford, L. A., Starliper, C. E., Teska, J. D., Nelson, J. T., \& Jensen, B. N. (1996). Control of external Aeromonas salmonicida: Topical disinfection of salmonids with chloramine-T. Journal of Aquatic Animal Health, 8(1), 52-57. https://doi.org/10.1577/1548-8667(1996) $008<0052:$ COEAST $>2.3 . \mathrm{CO} ; 2$
Densmore, C. L., \& Green, D. E. (2007). Diseases of amphibians. ILAR Journal/National Research Council, Institute of Laboratory Animal Resources, 48(3), 235-254. https://doi.org/10.1093/ilar.48.3.235

Diana, S. G., Beasley, V. B., \& Wright, K. M. (2001). Clinical toxicology. In K. M. Wright \& B. M. Whitaker (Eds.), Amphibian medicine and captive husbandry (pp. 223-232). Malabar FL: Krieger Publishing Company.

Dickinson, R. P., Bell, A. S., Hitchcock, C. A., Narayanaswami, S., Ray, S. J., Richardson, K., \& Troke, P. F. (1996). Novel antifungal 2-aryl-1-(1H-1,2,4-triazol-1-yl)butan-2-ol derivatives with high activity against Aspergillus fumigatus. Bioorganic and Medicinal Chemistry Letters, 6(16), 2031-2036. https://doi.org/10.1016/0960-894X(96)00363-0

Drake, G. J., Koeppel, K., \& Barrows, M. (2010). Disinfectant (F10SC) nebulisation in the treatment of "red leg syndrome" in amphibians. The Veterinary Record, 166(19), 593-594. https://doi.org/10.1136/vr. b4839

Edginton, A. N., Rouleau, C., Stephenson, G. R., \& Boermans, H. J. (2007). 2,4-D butoxyethyl ester kinetics in embryos of Xenopus laevis: The role of the embryonic jelly coat in reducing chemical absorption. Archives of Environmental Contamination and Toxicology, 52(1), 113-120. https://doi.org/10.1007/s00244-005-0215-4

El-Mofty, M. M., Abdelmeguid, N. E., Sadek, I. A., Essawy, A. E., \& Abdel Aleem, E. A. (2000). Induction of leukaemia in chloramphenicol-treated toads. Eastern Mediterranean Health Journal, 6(5-6), 1026-1034.

Fisher, M. C., Henk, D. A., Briggs, C. J., Brownstein, J. S., Madoff, L. C., McCraw, S. L., \& Gurr, S. J. (2012). Emerging fungal threats to animal, plant and ecosystem health. Nature, 484, 186-194. https://doi.org/ 10.1038/nature10947.Emerging

Fráter, M., Braunitzer, G., Urbán, E., Bereczki, L., Antal, M., \& Nagy, K. (2013). In vitro efficacy of different irrigating solutions against polymicrobial human root canal bacterial biofilms. Acta Microbiologica et Immunologica Hungarica, 60(2), 187-199. https://doi.org/10.1556/ AMicr.60.2013.2.9

Garner, T. W. J., Perkins, M. W., Govindarajulu, P., Seglie, D., Walker, S., Cunningham, A. A., \& Fisher, M. C. (2006). The emerging amphibian pathogen Batrachochytrium dendrobatidis globally infects introduced populations of the North American bullfrog, Rana catesbeiana. Biology Letters, 2(1), 455-459. https://doi.org/10.1098/rsbl.2006.0494

Gomez-Mestre, I., Touchon, J. C., \& Warkentin, K. M. (2006). Amphibian embryo and parental defenses and a larval predator reduce egg mortality from water mold. Ecology, 87(10), 2570-2581. https://doi.org/ 10.1890/0012-9658(2006)87[2570:AEAPDA]2.0.CO;2

Griffiths, R. A., \& Pavajeau, L. (2008). Captive breeding, reintroduction, and the conservation of amphibians. Conservation Biology, 22(4), 852-861. https://doi.org/10.1111/j.1523-1739.2008.00967.x

Groppelli, S., Pennati, R., De Bernardi, F., Menegola, E., Giavini, E., \& Sotgia, C. (2005). Teratogenic effects of two antifungal triazoles, triadimefon and triadimenol, on Xenopus laevis development: Craniofacial defects. Aquatic Toxicology, 73(4), 370-781. https://doi.org/10. 1016/j.aquatox.2005.04.004

Hadfield, C. A., \& Whitaker, B. R. (2005). Amphibian emergency medicine and care. Seminars in Avian and Exotic Pet Medicine, 14(2), 79-89. https://doi.org/10.1053/j.saep.2005.04.003

Hamdoun, A., \& Epel, D. (2007). Embryo stability and vulnerability in an always changing world. Proceedings of the National Academy of Sciences United States of America, 104(6), 1745-1750. https://doi.org/10. 1073/pnas.0610108104

Hansen, T. K., \& Falk-Petersen, I. B. (2001). Effects of egg disinfection and incubation temperature on early life stages of spotted wolffish. Aquaculture International, 9(4), 333-344. https://doi.org/10.1023/A: 1020437023395

Harboe, T., Huse, I., \& Oie, G. (1994). Effects of egg disinfection on yolk sac and first feeding stages of halibut (Hippoglossus hippoglossus L.) larvae. Aquaculture, 119(2-3), 157-165. https://doi.org/10.1016/00448486(94)90172-4 
Hettyey, A., Ujszegi, J., Herczeg, D., Holly, D., Vörös, J., Schmidt, B. R., \& Bosch, J. (2019). Mitigating disease impacts in amphibian populations: Capitalizing on the thermal optimum mismatch between a pathogen and its host. Frontiers in Ecology and Evolution, 7(July), 1-13. https:// doi.org/10.3389/fevo.2019.00254

Ho, S.-P., Hsu, T.-Y., Chen, M.-H., \& Wang, W.-S. (2000). Antibacterial effect of chloramphenicol, thiamphenicol and florfenicol against aquatic animal bacteria. The Journal of Veterinary Medical Science, 62 (5), 479-485. https://doi.org/10.1292/jvms.62.479

Holden, W. M., Ebert, A. R., Canning, P. F., \& Rollins-Smith, L. A. (2014). Evaluation of amphotericin $B$ and chloramphenicol as alternative drugs for treatment of chytridiomycosis and their impacts on innate skin defenses. Applied and Environmental Microbiology, 80(13), 4034-4041. https://doi.org/10.1128/AEM.04171-13

Johnson, M. L., \& Speare, R. (2003). Survival of Batrachochytrium dendrobatidos in water: Quarantine and disease control implications. Emerging, 9(8), 922-925.

Johnson, M. L., \& Speare, R. (2005). Possible modes of dissemination of the amphibian chytrid Batrachochytrium dendrobatidis in the environment. Diseases of Aquatic Organisms, 65, 181-186. https://doi.org/10. 3354/dao065181

Kiesecker, J. M., \& Blaustein, A. R. (1997). Influences of egg laying behaviour on pathogenic infection of amphibian eggs. Conservation Biology, 11(1), 214-220. https://doi.org/10.1046/j.1523-1739.1997.95509.x

Kiesecker, J. M., Blaustein, A. R., \& Belden, L. K. (2001). Complex causes of amphibian population declines. Nature, 410(6829), 681-684. https:// doi.org/10.1038/35070552

Kiesecker, J. M., Blaustein, A. R., \& Miller, C. L. (2001). Transfer of a pathogen from fish to amphibians. Conservation Biology, 15(4), 1064-1070. https://doi.org/10.1046/j.1523-1739.2001.0150041064.x

Laurila, A., Pakkasmaa, S., Crochet, P. A., \& Merilä, J. (2002). Predatorinduced plasticity in early life history and morphology in two anuran amphibians. Oecologia, 132(4), 524-530. https://doi.org/10.1007/ s00442-002-0984-7

Mahaney, P. A. (1994). Effects of freshwater petroleum contamination on amphibian hatching and metamorphosis. Environmental Toxicology and Chemistry, 13(2), 259-265. https://doi.org/10.1002/etc.5620130210

Martel, A., Van Rooij, P., Vercauteren, G., Baert, K., Van Waeyenberghe, L., Debacker, P., ... Pasmans, F. (2011). Developing a safe antifungal treatment protocol to eliminate Batrachochytrium dendrobatidis from amphibians. Medical Mycology, 49(2), 143-149. https://doi.org/10. 3109/13693786.2010.508185

McCallum, M. L. (2012). Disease and the dynamics of extinction. Philosophical Transactions of the Royal Society B: Biological Sciencesos, 367, 2828-2839. https://doi.org/10.1098/rstb.2012.0224

McDiarmid, R. W., \& Altig, R. (1999). Research: Materials and Techniques. In R. W. McDiarmid \& R. Altig (Eds.), Tadpoles: The biology of anuran larvae. Chicago: University of Chicago Press.

Miaud, C., Pozet, F., Gaudin, N. C. G., Martel, A., Pasmans, F., \& Labrut, S. (2016). Ranavirus causes mass die-offs of alpine amphibians in the Southwestern Alps (France). Journal of Wildlife Diseases, 52(2), 242-252. https://doi.org/10.7589/2015-05-113

Michel, C., Kerouault, B., \& Martin, C. (2003). Chloramphenicol and florfenicol susceptibility of fish-pathogenic bacteria isolated in France: Comparison of minimum inhibitory concentration, using recommended provisory standards for fish bacteria. Journal of Applied Microbiology, 95(5), 1008-1015. https://doi.org/10.1046/j.1365-2672.2003. 02093.x

Mikó, Z., Ujszegi, J., \& Hettyey, A. (2017). Age-dependent changes in sensitivity to a glyphosate-based pesticide in tadpoles of the common toad (Bufo bufo). Aquatic Toxicology, 187(March), 48-54. https://doi. org/10.1016/j.aquatox.2017.03.016

Miller, D. L., Rajeev, S., Brookins, M., Cook, J., Whittington, L., \& Baldwin, C. A. (2008). Concurrent infection with Ranavirus, Batrachochytrium dendrobatidis, and Aeromonas in a captive Anuran colony. Journal of Zoo and Wildlife Medicine, 39(3), 445-449. https:// doi.org/10.1638/2008-0012.1

Murray, K., Skerratt, L., Marantelli, G., Berger, L., Hunter, D., Mahony, M., \& Hines, H. (2011a). A report for the Australian Government Department of Sustainability, Environment, Water, Population and Communities: Guidelines for minimising disease risks associated with captive breeding, raising and restocking programs for Australian frogs (issue June).

Murray, K., Skerratt, L., Marantelli, G., Berger, L., Hunter, D., Mahony, M., \& Hines, H. (2011b). A report for the Australian Government Department of Sustainability, Environment, Water, Population and Communities: Hygiene protocols for the control of diseases in Australian frogs (issue June).

Nöllert, A., \& Nöllert, C. (1992). Die Amphibien Europas: BestimmungGefährdung-Schutz. Stuttgart: Franckh- Kosmos Verlag.

Nusbaum, K. E., \& Shotts, E. B. (1981). Action of selected antibiotics on four common bacteria associated with diseases of fish. Journal of Fish Diseases, 4(5), 397-404. https://doi.org/10.1111/j.1365-2761.1981. tb01149.x

Papis, E., Bernardini, G., Gornati, R., \& Prati, M. (2006). Triadimefon causes branchial arch malformations in Xenopus laevis embryos. Environmental Science and Pollution Research, 13(4), 251-255. https://doi.org/10. 1065/espr2006.01.014

Parker, J. M., Mikaelian, I., Hahn, N., \& Diggs, H. E. (2002). Clinical diagnosis and treatment of epidermal chytridiomycosis in African clawed frogs (Xenopus tropicalis). Comparative Medicine, 52(3), 265-268.

Pauli, B. D., Coulson, D. R., \& Berrill, M. (1999). Sensitivity of amphibian embryos and tadpoles to Mimic ${ }^{\circledR} 240$ LV insecticide following single or double exposures. Environmental Toxicology and Chemistry, 18(11), 2538-2544. https://doi.org/10.1002/etc.5620181122

Pessier, A. P. (2008). Management of disease as a threat to amphibian conservation. International Zoo Yearbook, 42(1), 30-39. https://doi.org/10. 1111/j.1748-1090.2008.00047.x

Poulter, R., Bishop, P., \& Speare, R. (2016). A protocol for treating chytrid (Batrachochytrium dendrobatidis)-infected frogs. downloaded in 2016.

R Development Core Team (2016). R: A language and environment for statistical computing. Vienna, Austria: R Foundation for Statistical Computing.

Scheele, B. C., Pasmans, F., Skerratt, L. F., Berger, L., Martel, A., Beukema, W., ... Canessa (2019). Amphibian fungal panzootic causes catastrophic and ongoing loss of biodiversity. Science, 363, 1459-1463. https://doi.org/10.1126/science.aav0379

Schloegel, L. M., Toledo, L. F., Longcore, J. E., Greenspan, S. E., Vieira, C. A., Lee, M., ... James, T. Y. (2012). Novel, panzootic and hybrid genotypes of amphibian chytridiomycosis associated with the bullfrog trade. Molecular Ecology, 21, 5162-5177. https://doi.org/10. 1111/j.1365-294X.2012.05710.x

Sutton, W. B., Gray, M. J., Hardman, R. H., Wilkes, R. P., Kouba, A. J., \& Miller, D. L. (2014). High susceptibility of the endangered dusky gopher frog to ranavirus. Diseases of Aquatic Organisms, 112(1), 9-16. https://doi.org/10.3354/dao02792

Tiboni, G. M. (1993). Second branchial arch anomalies induced by fluconazole, a bis-triazole antifungal agent, in cultured mouse embryos. Research Communications in Chemical Pathology and Pharmacology, 79 (3), 381-384.

Tóth, A. (1997). Dominance condition of Fusarium species occuring in winter wheat kernels in Pest County. Cereal Research Communications, 25 (3), 625-627. https://doi.org/10.1007/BF03543799

Van Rooij, P., Pasmans, F., Coen, Y., \& Martel, A. (2017). Efficacy of chemical disinfectants for the containment of the salamander chytrid fungus Batrachochytrium salamandrivorans. PLoS ONE, 12(10), 1-10. https:// doi.org/10.1371/journal.pone.0186269

Wagner, E. J., Oplinger, R. W., \& Bartley, M. (2012). Effect of single or double exposures to hydrogen peroxide or iodine on salmonid egg survival 
and bacterial growth. North American Journal of Aquaculture, 74, 84-91. https://doi.org/10.1080/15222055.2011.649887

Wassersug, R. J. (1976). A procedure for differential staining of cartilage and bone in whole formalin-fixed vertebrates. Stain Technology, 51(2), 131-134. https://doi.org/10.3109/10520297609116684

White, A. W. (2006). A trial using salt to protect green and golden bell frogs from chytrid infection. Herpetofauna, 36, 93-96.

Wilson, J. G. (1973). Environment and birth defects. New York: Academic Press.

Wind, E. (2002). Northern leopard frog (Rana pipiens) husbandry manual. A Report produced for the Columbia Basin Fish and Wildlife Compensation Program, Nelson, BC, and Columbia Basin Trust, Nakusp, BC. 1-65.

Woodward, A., Berger, L., \& Skerratt, L. F. (2014). In vitro sensitivity of the amphibian pathogen Batrachochytrium dendrobatidis to antifungal therapeutics. Research in Veterinary Science, 97(2), 365-367. https://doi. org/10.1016/j.rvsc.2014.06.013

Young, S., Speare, R., Berger, L., \& Skerratt, L. F. (2012). Chloramphenicol with fluid and electrolyte therapy cures terminally ill green tree frogs (Litoria caerulea) with chytridiomycosis. Journal of Zoo and Wildlife Medicine, 43(2), 330-337. https://doi.org/10.1638/2011-0231.1

Zippel, K., Johnson, K., Gagliardo, R., Gibson, R., McFadden, M., Browne, R., ... Townsend, E. (2011). The amphibian Ark: A global community for ex situ conservation of amphibians. Herpetological Conservation and Biology, 6(3), 340-352.
Zoupa, M., \& Machera, K. (2017). Zebrafish as an alternative vertebrate model for investigating developmental toxicity-The triadimefon example. International Journal of Molecular Sciences, 18(4), 817. https://doi.org/10.3390/ijms18040817

\section{SUPPORTING INFORMATION}

Additional supporting information may be found online in the Supporting Information section at the end of this article.

How to cite this article: Ujszegi J, Molnár K, Hettyey A. How to disinfect anuran eggs? Sensitivity of anuran embryos to chemicals widely used for the disinfection of larval and postmetamorphic amphibians. J Appl Toxicol. 2020;1-12. https:// doi.org/10.1002/jat.4050 